\title{
BIAYA PRODUKSI TEPUNG SAGU (Metroxylon sagu Rottb) SECARA SEMI MEKANIS PADA INDUSTRI USAHA KECIL DI DESA KOREK KECAMATAN SUNGAI AMBAWANG KABUPATEN KUBU RAYA
}

(Cost of Sago (Metroxylon sagu Rottb) Flour Semi-Mechanical Production at small business Industry in Korek, Village of Sungai Ambawang, Sub-District of Kubu Raya Regency)

\section{Julio Bagaskara, Gusti Hardiansyah, Dina Setyawati}

Fakultas Kehutanan Universitas Tanjungpura Jalan Daya Nasional Pontianak 78124

E-mail: juliobgskr@gmail.com

Abstract

Sago is a plant can be source of foods, and have a economic value. Production of sago flour need stages and experience. The purpose of this study is to describe the activity of sago flour production, analyze the cost, count revenue, and analyze advisability businesss sago flour production in Korek, Village of Sungai Ambawang, Sub-District of Kubu Raya Regency. This study uses survey method and interview technique. Production at Ako's industry includes: supplying basic materials, stripping, splitting, rasping, filtering, precipitating, drying, milling, and packaging. The total costs of production at Ako's industry is Rp 258.669,39/ hour, it is the sum of fixed costs and variable costs. Fixed costs are the cost of depreciation and capital interest is about Rp 3.717,47/ hour. Variable costs include the cost of basic materials, costs of transporting basic materials, employee salaries, fuel, packaging materials and delivery cost of raw materials is about $R p$ 254.951,92/ hour. Revenue of Ako's industry is $R p$ 410.576,92/ hour gotten from selling sago flour class $A$ is about 14 ton and selling sago flour class $B$ is about 3 ton. Net income of Ako's industry is Rp Rp 151.907,53/ hour. The based on the analysis, Ako's industry has $R / C$ value is 1,59. Because the value of $R / C$ more than 1 , so business of Ako's flour sago industry is profitable, and advisable to be run.

Keywords: Cost production, Diagram of sago flour production, $R / C$ analysis

\section{PENDAHULUAN}

Sagu (Metroxylon sagu Rottb) banyak dijumpai di Kalimantan Barat dan tumbuh secara alami pada lahan basah dan gambut (Maherawati dkk, 2011). Luas areal dan produksi sagu di Kalimantan Barat terus terjadi peningkatan dari 3 tahun terakhir. Pada tahun 2015 luas areal sagu 1.054 ha dan produksi sagu 241 ton. Pada tahun 2016 luas areal sagu 1.266 ha dan produksi sagu mencapai 292 ton. Pada tahun 2017, luas areal sagu mencapai 1.296 ha dengan jumlah produksi sagu mencapai 301 ton (Direktorat Jenderal Perkebunan, 2017).
Pengembangan lahan sagu dapat meningkatkan kualitas ketahanan pangan melalui spektrum pilihan konsumsi yang semakin luas. Pengembangan penganekaragaman konsumsi pangan nonberas ini tentu juga harus didukung oleh ketersediaan teknologi budidaya tanaman sagu yang adaptif (Alfons dan Arivin 2011).

Sagu merupakan hasil hutan bukan kayu yang dimanfaatkan masyarakat sebagai bahan pangan pengganti beras dan produk olahan traditional. Proses pengolahan sagu mulai dari menebang 
pohon sagu, membelah pohon sagu, menokok sagu, mengangkut ela sagu (hasil parutan empelur sagu) ke tempat pengolahan, perolehan hasil olahan berupa pati sagu yang dimasukkan ke dalam wadah atau tempat penampungan tepung sagu (goti). Dari tepung sagu ini akan diolah menjadi bermacam-macam makanan yang dapat diproduksi dalam skala industri kecil dan rumahtangga (Timisela, 2006).

Industri usaha kecil atau rumah tangga adalah sebagai salah satu kegiatan yang banyak dilakukan oleh petani di daerah pedesaan untuk peningkatan pendapatan keluarga. Industri kecil dan rumahtangga sangatlah penting sebab dapat menyerap kelebihan tenaga kerja di sektor pertanian dan memacu pertumbuhan ekonomi pedesaan. Itulah sebabnya pemerintah tetap mempertahankan program-program pembinaan bagi industri kecil dan industri rumahtangga di pedesaan (Suratiyah, 2008). Di Desa Korek terdapat industri kecil tepung sagu yang terletak di Kecamatan Sungai Ambawang Kabupaten Kubu Raya Kalimantan Barat, luas wilayah Desa Korek \pm 25.000 Ha. Tipologi desa merupakan petani/ pekebun. Walaupun produksi dilakukan untuk tujuan komersial, namun industri belum memahami secara rinci struktur biaya dan besar pendapatannya serta analisa kelayakan usaha dari industri tersebut. Oleh karena itu, dilakukan penelitian untuk mengetahui bagaimanaa tahapan industri memproduksi tepung sagu, menganalisa biaya, menghitung pendapatan dan menganalisa kelayakan usaha produksi tepung sagu di industri usaha kecil Desa Korek Kecamatan Sungai Ambawang Kabupaten Kubu Raya.

\section{METODE PENELITIAN}

Penelitian dilaksanakan di industri tepung sagu Ako di Desa Korek Kecamatan Sungai Ambawang Kabupaten Kubu Raya Kalimantan Barat. Waktu penelitian dilakukan selama \pm 4 minggu efektif dilapangan.

\section{Prosedur Penelitian}

Penelitian ini dilaksanakan di Industri Tepung Sagu Ako di Desa Korek Kecamatan Sungai Ambawang Kabupaten Kubu Raya dengan menggunakan metode survei melalui wawancara mendalam (indepth interview) terhadap pemilik industri untuk mendapatkan data tentang output input ekonomi yang terjadi pada industri tepung sagu. Metode penelitian ini juga mengunakan metode survei. Data yang akan dikumpulkan yaitu data primer dan data sekunder. Data primer dalam penelitian yaitu biaya tetap dan biaya variabel, jumlah produksi, dan harga jual dari produksi tepung sagu. Data sekunder adalah data penunjang yang berhubungan dengan masalah penelitian yang diperoleh dari studi literatur dan sumber terkait.

\section{Analisis Data}

Data yang terkumpul selanjutnya diolah dengan cara deskripsi, dokumentasi, dan tabulasi. Data yang akan dianalisa berkaitan dengan nilai ekonomi produksi tepung sagu di Desa Korek. Analisis data dalam penelitian ini, ialah sebagai berikut:
1. Menghitung
Biaya
Produksi (Soekartawi, 2003):

$$
\mathrm{TC}=\mathrm{FC}+\mathrm{VC}
$$


Keterangan :

$$
\begin{array}{ll}
\mathrm{TC} & =\text { Total Cost (biaya total) } \\
\mathrm{FC} & =\text { Fixed cost (biaya tetap) } \\
\mathrm{VC} & =\text { Variebel Cost (Biaya tidak tetap) }
\end{array}
$$

\section{Menghitung Depresiasi menurut} (Nugroho, 2002)

$$
\mathrm{D}=\frac{\mathrm{M}-\mathrm{R}}{\mathrm{N}}
$$

Keterangan :

$$
\begin{aligned}
& \mathrm{D} \quad=\text { Depresiasi } \\
& \mathrm{M} \quad=\text { Modal yang digunakan } \\
& \mathrm{R} \quad=\text { Harga Rongsokan (10\% dari } \\
& \text { harga beli) } \\
& \mathrm{N} \quad=\text { Umur ekonomis (tahun) }
\end{aligned}
$$

\section{Menghitung Bunga Modal} (Nugroho, 2002)

Bunga Modal Pertahun =

$$
\left[\left\{\frac{(\mathbf{M}-\mathbf{R})(\mathbf{N}+\mathbf{1})}{2 . \mathbf{N} !}+R\right\} x i\right]
$$

Keterangan

$\mathrm{M}$ = Modal yang digunakan

$\mathrm{R}=$ Harga Rongsokan $(10 \%$ dari harga beli)

$\mathrm{N}=$ Umur ekonomis (tahun)

I = Tingkat bunga yang diharapkan $(10,71 \%)$

\section{Menghitung}

\section{Penerimaan}

(Soekartawi, 2003)

$$
\mathrm{TR}=\mathrm{P} \times \mathrm{Q}
$$

Keterangan :

$$
\begin{array}{ll}
\text { TR } & =\text { Total Penerimaan } \\
\mathrm{P} & =\text { Harga Jual Per satuan Unit } \\
\mathrm{Q} & =\text { Jumlah Output yang dijual }
\end{array}
$$

\section{Menghitung Pendapatan Bersih} (Soekartawi, 2003)

$$
\pi=\mathrm{TR}-\mathrm{TC}
$$

Keterangan :

$$
\begin{array}{ll}
\pi & =\text { Keuntungan Aktual } \\
\text { TR } & =\text { Total Penerimaan / Total Revenue } \\
\text { TC } & =\text { Total Cost }
\end{array}
$$

\section{Rasio R/C (Firdaus 2008)}

$$
\mathrm{R} / \mathrm{C} \text { rasio }=\frac{\mathrm{TR}}{\mathrm{TC}}
$$

Dimana

$\mathrm{R} / \mathrm{C}$ rasio = Imbangan penerimaan dan biaya

TR = Total penerimaan TC = Total biaya

Jika nila $\mathrm{R} / \mathrm{C}$ rasio > 1 , berarti usaha industri tepung sagu menguntungkan dan layak untuk diusahakan,

Jika nilai $\mathrm{R} / \mathrm{C}$ rasio $<1$, berarti usaha industri tepung sagu tidak menguntungkan dan tidak layak untuk diusahakan.

\section{HASIL DAN PEMBAHASAN}

\section{Karakteristik Industri Tepung Sagu}

Industri tepung sagu memiliki ciri khusus yaitu berada di dekat aliran sungai, yang bertujuan untuk mempermudah dalam proses transportasi bahan baku melalui jalur air. Pada umumnya tumbuhan sagu tumbuh di tepian sungai. Sehingga transportasi akan lebih mudah melalui jalur air. Bahan baku berupa sagu batang memiliki panjang $90 \mathrm{~cm}$ hingga $110 \mathrm{~cm}$ diikat menjadi rakit dan ditarik menggunakan kapal kelotok. Industri tepung sagu Ako beroperasi apabila persediaan bahan baku tersedia dan adanya permintaan pemasaran. jika bahan baku tersedia dan terdapat permintaan pemasaran, maka industri akan beroperasi untuk menghasilkan produk berupa tepung sagu.

Nugroho (2002) mengklasifikasikan perhitungan biaya berdasarkan sistem operasinya. Perbedaan sistem operasi mempengaruhi cara perhitungan biaya produksi. Sistem operasi dan cara perhitungannya dapat dilihat pada Tabel 1 . 
Tabel 1. Sistem Operasi dan Perhitungan Biaya (Operation System and Cost Calculation)

\begin{tabular}{|c|c|c|}
\hline & \multicolumn{2}{|c|}{ Sistem Operasi } \\
\hline & Berdasarkan pesanan & Beroperasi secara massal \\
\hline 1.Ciri khusus & $\begin{array}{l}\text { Beroperasi berdasarkan pesanan } \\
\text { dari pihak lain }\end{array}$ & $\begin{array}{l}\text { Beroperasi untuk memenuhi } \\
\text { persediaan barang }\end{array}$ \\
\hline 2.Jumlah produk & Berdasarkan jumlah pesanan & $\begin{array}{l}\text { Berdasarkan jumlah produksi per } \\
\text { periode produksi }\end{array}$ \\
\hline 3.Biaya per unit & $\begin{array}{l}\text { Dihitung berdasarkan jumlah } \\
\text { biaya untuk menyelesaikan } \\
\text { kontrak dibagi dengan jumlah } \\
\text { pesanan dalam kontrak }\end{array}$ & $\begin{array}{l}\text { Dihitung berdasarkan jumlah biaya } \\
\text { per periode produksi dibagi jumlah } \\
\text { produksi per periode tersebut }\end{array}$ \\
\hline 4.Metode hitung & Metode biaya produksi pesanan & Metode biaya Proses \\
\hline
\end{tabular}
Sumber: Nugroho (2002), Analisa Biaya Proyek Kehutanan

Industri Ako melakukan kegiatan produksinya untuk memenuhi persediaan tepung sagu. Jika bahan baku tersedia, maka industri akan memproduksi tepung sagu secara terus menerus untuk memenuhi permintaan pemasaran tepung sagu. Nugroho (2002) menyatakan bahwa industri yang beroperasi secara massal memiliki ciri khusus yaitu melaksanakan kegiatan produksinya untuk memenuhi persediaan produk, dan memproduksi secara terus-menerus selama persediaan produk diperlukan. Sesuai dengan pernyataan tersebut, maka industri tepung sagu ako di kategorikan sebagai industri yang berproduksi secara massal sehingga perhitungan biaya per unit menggunakan metode biaya proses. Produksi tepung sagu berdasarkan alat dan cara pengelolaannya pada umumnya dapat dibedakan menjadi tradisional, semi mekanis, dan mekanis. Pada industri usaha kecil umumnya hanya secara tradisional dan semi mekanis. Produksi tepung sagu secara tradisional umumnya dilakukan untuk memenuhi kebutuhan sehari-hari.

\section{Proses Produksi Tepung Sagu}

Proses produksi tepung sagu di industri ako dilakukan secara semi mekanis yaitu dilakukan secara manual menggunakan alat dan dibantu mesin mekanis. Tahapan kegiatan yang dilakukan industri Ako dapat dilihat pada Gambar 1: 

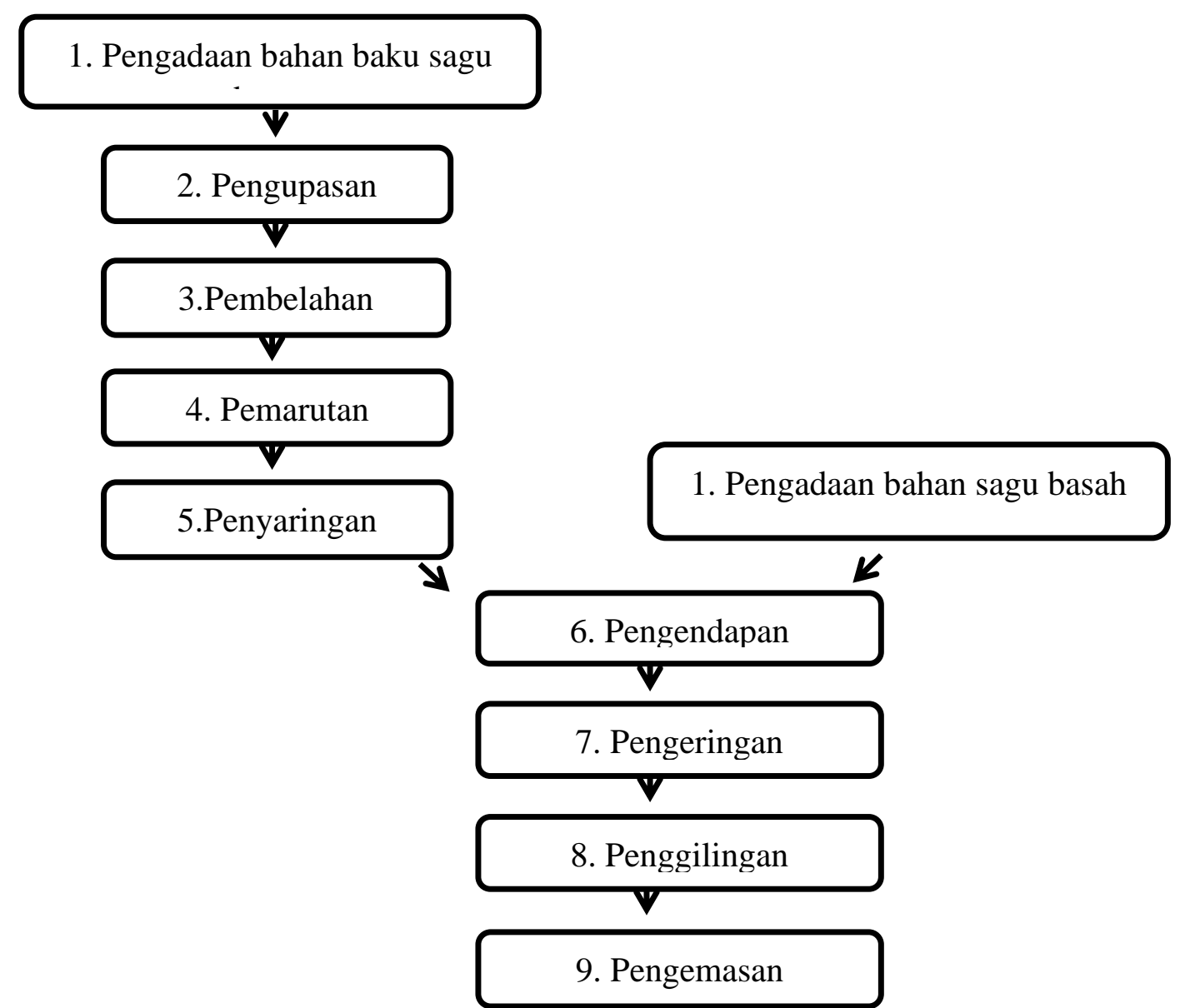

Gambar 1. Diagram Produksi Tepung Sagu (Diagram of sago flour production)

Pengadaan bahan baku. Bahan baku dalam produksi tepung sagu ialah batang sagu yang diperoleh dengan cara dibeli dalam bentuk potongan $90 \mathrm{~cm}$ hingga $110 \mathrm{~cm}$. Batang sagu yang dibeli pada industri ako diikat menggunakan tali tambang menjadi rakit, kemudian dihanyutkan melalui sungai lalu ditarik menggunakan motor air menuju lokasi industri tepung sagu ako. Selain sagu batang, bahan yang dibeli ialah sagu basah, yaitu sagu yang telah diparut dan masih basah, lalu diolah mulai dari tahap pengendapan. Bahan yang telah siap, selanjutnya diolah.

Pengupasan. Tujuan pengupasan ialah untuk memisahkan kulit luar yang keras dengan empulur sagu. Pengupasan kulit batang sagu dilakukan secara manual dengan menggunakan linggis. Batang sagu ditahan posisinya menggunakan kaki agar tidak bergerak, lalu kulit batang sagu ditusuk bagian kulitnya menggunakan linggis. Linggis mengitari bagian dalam dari kulit batang sagu sehingga kulit terlepas dari batang sagu.

Pembelahan. Setelah batang sagu dikupas, batang sagu yang telah terpisah dari kulit sagu dibelah menggunakan kapak secara manual menjadi enam bagian. Batang sagu dibelah sejajar dengan diameter batang, sehingga tetap memiliki panjang yang sama tetapi diameter yang lebih kecil. Batang sagu 
dibelah secara manual dengan menggunakan kapak manual.

Pemarutan. Batang sagu yang telah dibelah selanjutnya diparut menggunakan alat pemarut dengan tenaga mesin, tetapi batang sagu didorong ke alat pemarut secara manual. Mesin menggerakan alat pemarut sehingga alat pemarut berputar dan selanjutnya batang sagu yang telah dibelah didorong menggunakan tangan sehingga batang tersebut terparut oleh alat pemarut.

Penyaringan. Proses selanjutnya ialah proses penyaringan yaitu batang sagu yang telah diparut akan otomatis melewati proses penyaringan. Alat penyaringan ialah jaring plastik yang direkatkan pada kayu, selanjutnya kayu tersebut digerakan menggunakan tenaga mesin diesel. Pada proses penyaringan, saringan selalu dialiri dengan air agar tetap basah dan pati sagu dapat terpisah dari ampas sagu. Penyaringan bertujuan untuk memisahkan pati sagu dengan ampas sagu. Pada proses penyaringan ampas akan terbuang dan pati akan masuk kedalam saringan menuju tempat penampungan.

Pengendapan. Setelah masuk ke dalam tempat penampungan, pati sagu dibiarkan kurang lebih 4 jam di dalam wadah penampungan agar pati sagu tersebut mengendap dan menjadi pasta. Setelah 4 jam, air di dalam wadah dibuang, dan hasil endapan pati sagu berupa pasta dimasukan ke dalam karung selama kurang lebih 2 jam, hal ini dilakukan supaya kadar air pasta tersebut berkurang.

Pengeringan. Pati sagu berbentuk pasta selanjutnya dijemur dibawah sinar matahari supaya kadar airnya berkurang. Pasta sagu dijemur di atas terpal agar tidak kotor. Jika cuaca hujan maka pati tersebut akan disimpan didalam wadah agar tidak terkena air hujan sehingga tetap kering.

Penggilingan. Setelah pasta sagu mengering menjadi tepung kasar selanjutnya tepung kasar tersebut digiling hingga halus menjadi tepung yang halus. Proses penggilingan dilakukan secara semimekanis. Alat penggiling digerakan menggunakan tenaga mesin dompeng, tetapi tepung dimasukan ke dalam mesin penggiling secara manual.

Pengemasan. Tepung sagu yang telah digiling selanjutnya dimasukan ke dalam karung 25kg. Proses pengemesan dilakukan secara manual. Setelah tepung sagu dikemas selanjutnya tepung siap dijual ke pasar-pasar di Pontianak dan sekitarnya.

\section{Biaya Produksi Tepung Sagu}

Produksi dan biaya produksi adalah hal yang sangat berkaitan, dari proses produksi tepung sagu yang terjadi di industri tepung sagu ako di Desa Korek data direkapitulasi setiap kegiatan, selanjutnya dapat diketahui alat dan mesin serta bahan yang terdapat pada proses produksi tepung sagu tersebut. Setelah direkapitulasi maka dapat ditentukan biaya-biaya yang terjadi, pengeluaran dan pemasukan dana pada industri tepung sagu secara semi mekanis di Desa Korek. Biaya yang terjadi diukur dengan nilai mata uang rupiah. Biaya produksi merupakan biayabiaya yang diperlukan untuk mengolah bahan baku sagu menjadi produk tepung sagu yang siap untuk dijual. 
Penggolongan biaya berdasarkan prilaku terhadap perubahan volume kegiatan diklasifikasikan menjadi dua yaitu biaya tetap (fixed cost) dan biaya variabel (variable cost). Biaya tetap adalah biaya yang relatif tetap jumlahnya dan terus dikeluarkan walaupun produksi yang diperoleh banyak atau sedikit. Biaya variabel adalah biaya yang besar kecilnya dipengaruhi oleh produksi yang diperoleh, contoh biaya untuk tenaga kerja. Total biaya adalah jumlah dari biaya tetap dan biaya variabel (Nugroho, 2002). Sejalan dengan pendapat tersebut, biaya produksi pada industri Ako diklasifikasikan menjadi biaya tetap dan biaya variabel.

\section{Biaya Tetap}

Biaya tetap sebagai biaya yang jumlahnya tidak berubah dalam rentang waktu tertentu, berapa pun besarnya penjualan atau produksi perusahaan. Dari pernyataan tersebut dapat disimpulkan bahwa biaya tetap yang dikeluarkan setiap bulannya pada produksi tepung sagu di industri ako tidak berpengaruh terhadap banyaknya jumlah produksi tepung sagu yang dihasilkan (Kuswadi, 2005). Pada penelitian ini biaya tetap dalam industri Ako meliputi biaya penyusutan dan bunga modal. Biaya tetap dari produksi tepung sagu adalah sebesar Rp3.717,47/ jam merupakan jumlah dari biaya penyusutan sebesar Rp 2.206,01/ jam dan bunga modal sebesar Rp 1.511,46/ jam. Biaya tetap pada Industri Ako merupakan biaya yang tetap dikeluarkan setiap bulannya walaupun Industri Ako tidak memproduksi tepung sagu. Rincian dan persentase biaya penyusutan dapat dilihat pada Tabel 2:

Tabel 2. Biaya Penyusutan (Depreciation Cost)

\begin{tabular}{llcc}
\hline No & Alat dan Mesin & Penyusutan Rp/jam & Persentase (\%) \\
\hline 1 & Kapak & 11,54 & 0,52 \\
2 & Linggis & 14,42 & 0,65 \\
3 & Mesin Diesel Besar & 324,52 & 14,71 \\
4 & Mesin Diesel kecil & 649,04 & 29,42 \\
5 & Alat Pemarut & 108,17 & 4,90 \\
6 & Alat Penggiling & 324,52 & 14,71 \\
7 & Biaya Bangunan & 504,81 & 22,88 \\
8 & Cangkul Lurus & 11,54 & 0,52 \\
9 & Tali Tambang & 8,65 & 0,39 \\
10 & Terpal(2mx100m) & 108,17 & 4,90 \\
11 & Mesin Jahit & 54,09 & 2,45 \\
12 & Timbangan & 86,54 & 3,92 \\
\hline \multicolumn{2}{c}{ Total Penyusutan } & $\mathbf{2 . 2 0 6 , 0 1}$ & $\mathbf{1 0 0 \%}$ \\
\hline
\end{tabular}

Metode perhitungan penyusutan yang digunakan menggunakan metode depresiasi yang paling sederhana dan banyak digunakan yaitu metode garis lurus, sehingga beban depresiasi tiap periode jumlahnya sama (Baridwan, 2008). Sesuai dengan pernyataan tersebut, perhitungan penyusutan pada penelitian ini juga menggunakan metode garis lurus. Tabel 2, biaya penyusutan mesin diesel merupakan biaya penyusutan yang paling besar yang dikeluarkan industri sebesar Rp 649,04/ jam (29,42\%) untuk 3 unit 
mesin diesel 8HP dan Rp 324,52/ jam $(14,71 \%)$ untuk 1 unit mesin diesel 20HP, sehingga biaya yang dikeluarkan untuk penyusutan mesin diesel ialah sebesar Rp 973,56/jam. Biaya penyusutan bangunan merupakan biaya terbesar kedua setelah biaya penyusutan mesin yaitu sebesar Rp 504,81/jam dengan persentase $22,88 \%$ dari total biaya penyusutan. Selanjutnya biaya yang dikeluarkan industri adalah biaya penyusutan alat penggiling $(14,71 \%)$, alat pemarut $(4,90 \%)$, terpal $(4,90 \%)$, timbangan $(3,92 \%)$, mesin jahit
$(2,45 \%), \quad$ linggis $(0,65 \%)$, $\operatorname{kapak}(0,52 \%)$, cangkul lurus $(0,52 \%)$, dan tali tambang $(0,39 \%)$.

Selain biaya penyusutan, biaya tetap dalam penelitian ini juga mencangkup bunga modal. Bunga modal diperlukan sebagai kompensasi atas uang yang diinventasikan. Pada penelitian ini tingkat bunga Bank yang digunakan adalah rata-rata bunga Bank Indonesia dalam tiga tahun terakhir yaitu sebesar $10,71 \%$. Rincian serta persentase bunga modal dapat dilihat pada Tabel 3.

Tabel 3. Bunga modal (Capital Interest)

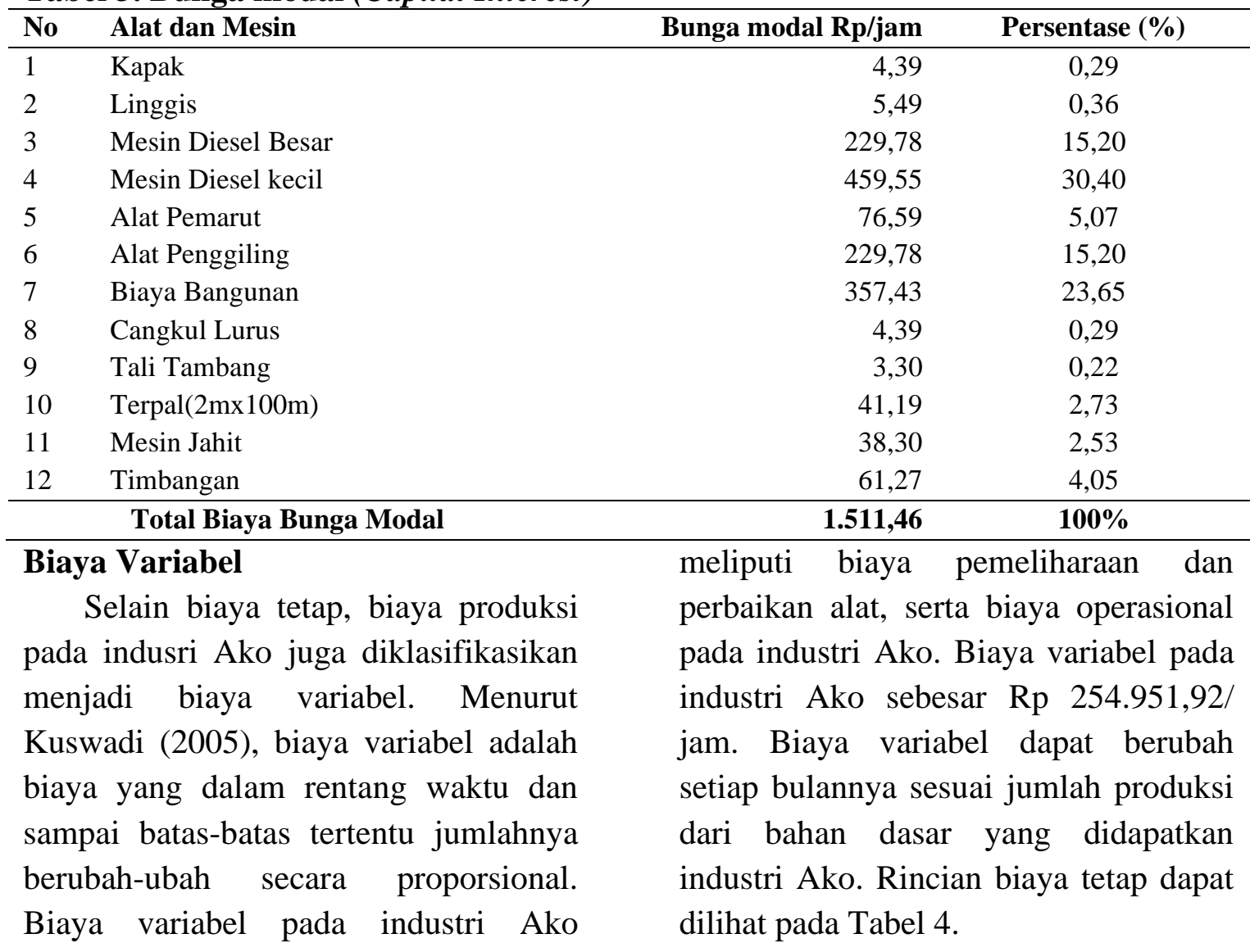


Tabel 4. Biaya Variabel (Variable Cost)

\begin{tabular}{llrc}
\hline No & Komponen & Rp/ jam & Persentase (\%) \\
\hline 1 & Upah Tenaga Kerja & $41.250,00$ & 16,18 \\
2 & Bahan Baku Sagu Batang & $57.692,31$ & 22,63 \\
3 & Bahan Baku Sagu Basah & $120.192,31$ & 47,14 \\
4 & Sewa Motor Air & $1.923,08$ & 0,75 \\
5 & Karung (25kg) & $7.692,31$ & 3,02 \\
6 & Oli Perawatan Mesin diesel & $1.153,85$ & 0,45 \\
7 & BBM (solar) & $18.028,85$ & 7,07 \\
8 & Biaya Transportasi antar Tepung Sagu & $6.730,77$ & 2,64 \\
9 & Benang Jahit & 288,46 & $0,11 \%$ \\
\hline & Total Biaya Variabel & $\mathbf{2 5 4 . 9 5 1 , 9 2}$ & $\mathbf{1 0 0 \%}$
\end{tabular}

Biaya variabel adalah biaya yang per satuan unit produksinya tetap, tetapi akan berubah jumlah totalnya jika volume produksinya berubah. Biaya veriabel tidak diperlukan apabila tidak berproduksi. Uraian rinci biaya variabel banyak sekali tergantung dari kegiatan usaha apa yang ditekuni (Nugroho, 2002). Pada penelitian di industri Ako biaya variabel meliputi biaya upah 3 orang tenaga kerja, 400 batang bahan dasar, biaya 1 kali transportasi sewa motor air untuk menarik bahan dasar, biaya pembelian 10 ton bahan sagu basah yang akan diolah menjadi tepung sagu, 12 liter oli perawatan mesin dompeng, 500 liter bahan bakar solar, biaya pengemasan berupa 800 buah karung $25 \mathrm{Kg}$ dan 1 bal benang jahit, dan biaya transportasi pengiriman tepung sagu.

Berdasarkan hasil analisis data biaya variabel, diketahui bahwa urutan biaya terbesar ialah biaya pembelian bahan dasar 10 ton sagu basah dengan persentase sebesar $47,14 \%$ dari total biaya variabel. Biaya selanjutnya ialah biaya 400 batang bahan baku dengan persentase sebesar $22,63 \%$ dari total biaya variabel, upah 3 karyawan dengan persentase sebesar $16,18 \%$. Biaya variabel yang dikeluarkan industri selanjutnya ialah biaya bahan bakar solar $(7,07 \%)$, karung $(3,02)$, biaya transportasi antar tepung sagu $(2,64 \%)$, sewa motor air untuk penarikan rakit bahan dasar $(0,75 \%)$, oli perawatan mesin diesel $(0,45 \%)$, dan pembelian benang jahit $(0,11 \%)$ yang digunakan untuk mengemasan tepung ke dalam karung.

\section{Total Biaya Produksi}

Biaya total yang dikeluarkan oleh suatu industri dapat dihitung dengan menggunakan rumus matematis. Total biaya produksi tepung sagu merupakan penjumlahan dari biaya tetap dan biaya variabel yang dikeluarkan oleh (Soekartawi, 2003). Total biaya produksi tepung sagu Industri Ako ialah sebesar Rp 258.669,39/ jam. Biaya tetap pada analisa biaya di industri ako ialah sebesar Rp 3.717,47/ jam terdiri dari biaya penyusutan dan biaya bunga modal, sedangkan biaya variabel sebesar Rp 254.951,92/ jam terdiri dari biaya upah tenaga kerja, biaya bahan baku, bahan bakar solar, biaya oli perawatan, biaya sewa transportasi, dan biaya karung serta benang. Persentase 
biaya variabel lebih besar daripada biaya tetap Industri Ako, dikarenakan Industri Ako memerlukan biaya variabel yang besar untuk membeli bahan baku dengan maksud memproduksi tepung sagu dalam jumlah besar. Jika biaya variabel pembelian bahan baku yang dikeluarkan industri Ako kecil maka jumlah produksi tepung sagu juga kecil. Rincian total biaya produksi tepung sagu dapat dilihat pada Tabel 5.

Tabel 5. Biaya Total (Total Cost)

\begin{tabular}{llrc}
\hline No & Jenis Biaya & $\mathrm{Rp} / \mathrm{jam}$ & Persentase $(\%)$ \\
\hline $\mathbf{1}$ & Biaya Tetap & & \\
& Biaya Penyusutan & $2.206,01$ & 0,85 \\
& Bunga Modal & $1.511,46$ & 0,58 \\
\hline & Jumlah biaya tetap & $\mathbf{R p ~ 3 . 7 1 7 , 4 7}$ & $\mathbf{1 , 4 4}$ \\
\hline $\mathbf{2}$ & Biaya Variabel & & \\
& Upah Karyawan & $41.250,00$ & 15,95 \\
& Bahan Baku Sagu Batang & $57.692,31$ & 22,30 \\
& Sagu Basah & $120.192,31$ & 46,47 \\
& Sewa Motor Air & $1.923,08$ & 0,74 \\
& Karung (25kg) & $7.692,31$ & 2,97 \\
& Oli Perawatan Mesin diesel & $1.153,85$ & 0,45 \\
& BBM (solar) & $18.028,85$ & 6,97 \\
& Biaya Transportasi Tepung Sagu & $6.730,77$ & 2,60 \\
& Benang Jahit & 288,46 & 0,11 \\
\hline & Jumlah biaya variabel & $\mathbf{R p ~ 2 5 4 . 9 5 1 , 9 2}$ & $\mathbf{9 8 , 5 6}$ \\
\hline $\mathbf{3}$ & Total Biaya Produksi & $\mathbf{R p ~ 2 5 8 . 6 6 9 , 3 9}$ & $\mathbf{1 0 0}$ \\
\hline
\end{tabular}

Keterangan : Persentase biaya merupakan persentase dari total biaya produksi

Tabel 5 menjelaskan bahwa biaya variabel lebih besar dibandingkan biaya tetap. Biaya variabel mendominasi dalam produksi tepung sagu dikarenakan tingginya harga bahan baku yang dibeli. persentase biaya variabel lebih besar daripada biaya tetap industri Ako. Industri Ako memerlukan biaya variabel yang besar untuk membeli bahan dasar dengan maksud memproduksi tepung sagu dalam jumlah besar. Jumlah biaya variabel Industri Ako sebesar 98,56 5 dari total biaya produksi. Jika biaya variabel pembelian bahan dasar yang dikeluarkan industri Ako kecil maka jumlah produksi tepung sagu juga kecil

\section{Pendapatan Industri}

Harga adalah unsur penting dalam menentukan pendapatan perusahaan, karena pendapatan perusahaan atau total revenue (TR) adalah hasil kali dari harga (p) dengan kuantitas (q) yang terjual (Homas, 2001). Pendapatan industri tepung sagu dihitung dari jumlah produksi dikali dengan harga jual, dengan demikian, tingkat pendapatan searah dengan hasil produksi, semakin tinggi hasil produksi maka pendapatan akan semakin tinggi.

Perbedaan kualitas sagu juga mempengaruhi harga jual. Sagu kelas A adalah tepung sagu yang memiliki warna putih. Tepung Sagu kelas A merupakan sagu yang pada proses pengendapan terletak pada bagian paling bawah. Berdasarkan hasil analisis industri ako dapat menghasilkan tepung sagu kelas $\mathrm{A}$ sebanyak $82 \%$ dari total jumlah produksi. Sedangkan sagu kelas B hanya 18\% dari jumlah total produksi. Sagu kelas B merupakan sagu yang terletak pada bagian 
atas pada saat proses pengendapan. Harga jual sagu kelas A ialah Rp 5.200.000/ton dan harga jual sagu kelas B adalah Rp 4.200.000/ton. Total pendapatan dapat dilihat pada Tabel 6 .

Tabel 6. Pendapatan Produksi Tepung Sagu (Revenue of Sago Flour Production)

\begin{tabular}{ccccc}
\hline & $\begin{array}{c}\text { Jumlah Produksi } \\
\text { (ton /bulan) }\end{array}$ & Harga Jual (Rp) & Biaya (Rp/bulan) & Rp/jam \\
\hline Sagu kelas A & 14 & $5.200 .000,00$ & $72.800 .000,00$ & $350.000,00$ \\
Sagu kelas B & 3 & $4.200 .000,00$ & $12.600 .000,00$ & $60.576,92$ \\
Pendapatan & 17 & & $\mathbf{8 5 . 4 0 0 . 0 0 0 , 0 0}$ & $410.576,92$ \\
Biaya Produksi & & & & $258.669,39$ \\
Pendapatan aktual & & & & $151.907,53$ \\
\hline Tabel 6 & menyatakan & & & \\
\hline
\end{tabular}

pendapatan Industri Ako adalah sebesar Rp410.576,92/ jam yang merupakan pendapatan dari hasil penjualan 14 ton tepung sagu kelas A dan 3 ton tepung sagu kelas B. Pendapatan bersih dari produksi tepung sagu ialah total pendapatan dikurang total biaya yaitu sebesar $\mathrm{Rp}$ 151.907,53/ jam.

\section{Kelayakan Usaha Industri}

Kelayakan usaha umumnya dihitung berdasarkan rasio antara pendapatan dan pengeluaran. Jika pendapatan lebih besar daripada pengeluaran maka usaha tersebut dikatakan menguntungkan. Firdaus (2008) menggunakan rumus R/C Ratio (Revenue
Cost Ratio) untuk menganalisa kelayakan usaha produksi. Jumlah penerimaan yang diperoleh industri ako ialah sebesar Rp 410.576,92/ jam dan jumlah biaya produksi sebesar Rp258.669,39/ jam, sehingga niilai $\mathrm{R} / \mathrm{C}=1,59$. Karena nilai $\mathrm{R} / \mathrm{C}$ lebih besar daripada 1 maka usaha industri tepung sagu Ako menguntungkan dan layak untuk diusahakan. Besarnya biaya untuk mendapatkan bahan baku sagu batang dan sagu basah menjadi faktor nilai $\mathrm{R} / \mathrm{C}$ pada industri ako lebih kecil. Usaha industri tepung sagu yang mengurangi besarnya biaya, Rincian analisis $\mathrm{R} / \mathrm{C}$ rasio dapat dilihat pada Tabel 7.

Tabel 7. Analisis rasio R/C (Analysis of $R / C$ Ratio)

\begin{tabular}{llrc}
\hline No & Jenis Biaya & Rp/ jam & Persentase $(\%)$ \\
\hline 1 & Total Penerimaan & $\mathbf{4 1 0 . 5 7 6 , 9 2}$ & $\mathbf{1 0 0}$ \\
\hline 2 & Biaya Tetap & $\mathbf{3 . 7 1 7 , 4 7}$ & 0,9 \\
& Biaya Penyusutan & $2.206,01$ & \\
& Bunga Modal & $1.511,46$ & \\
\hline 3 & Biaya Variabel & $\mathbf{2 5 4 . 9 5 1 , 9 2}$ & 62,1 \\
& Upah Karyawan & $41.250,00$ & \\
& Bahan Dasar Sagu Batang & $57.692,31$ & \\
& Sagu Basah & $120.192,31$ & \\
& Sewa Motor Air & $1.923,08$ & \\
& Karung (25kg) & $7.692,31$ & \\
& Oli Perawatan Mesin diesel & $1.153,85$ & \\
& BBM (solar) & $18.028,85$ & \\
& Biaya Transportasi antar Tepung Sagu & $6.730,77$ & \\
& Benang Jahit & 288,46 & \\
& Total Biaya Produksi & $\mathbf{2 5 8 . 6 6 9 , 3 9}$ & 63 \\
\hline $\mathbf{4}$ & Pendapatan Aktual & $\mathbf{1 5 1 . 9 0 7 , 5 3}$ & 37 \\
\hline $\mathbf{5}$ & R/C rasio & $\mathbf{1 , 5 9}$ & \\
\hline
\end{tabular}


Tabel 7 mengungkapkan bahwa nilai $\mathrm{R} / \mathrm{C}$ sebesar 1,59 dihitung berdasarkan perbandingan antara penerimaan dengan total biaya produksi tepung sagu. Nilai $\mathrm{R} / \mathrm{C}$ rasio sebesar 1,59 menyatakan bahwa setiap pengeluaran biaya produksi sebesar Rp1,00 maka akan menghasilkan penerimaan sebesar $\mathrm{Rp}$ 1,59. Secara matematis pendapatan aktual atau laba industri tepung sagu di Desa Korek sebesar 59\% dari besarnya total biaya yang dikeluarkan. Karena nilai R/C lebih dari 1 maka hal ini menyatakan bahwa usaha tepung sagu di Desa Korek menguntungkan dan kayak untuk diusahakan.

Dalam suatu produksi diusahakan untuk mencapai efisiensi produksi, yaitu menghasilkan barang dan jasa dengan biaya yang paling rendah untuk mendapatkan hasil yang optimum (Miller dan Meiners, 2000). Hal ini sesuai dengan teori ekonomi bahwa biaya produksi berpengaruh negatif terhadap tingkat keuntungan, artinya setiap penambahan satu satuan biaya akan mengurangi satu satuan tingkat keuntungan (Muin, S, 2011). Hasil analisis $\mathrm{R} / \mathrm{C}$ rasio selain digunakan untuk mengukur kelayakan suatu unit usaha, juga dapat digunakan untuk mengukur tingkat efisiensi penggunaan input produksi yang digunakan untuk memproduksi suatu produk. Nilai R/C rasio lebih dari 1 (satu) menunjukan penggunaan input produksi sudah efisien (Muin, 2011). Hasil analisis $\mathrm{R} / \mathrm{C}$ rasio produksi tepung sagu menunjukan nilai lebih dari satu, hal ini berarti penggunaan input produksi di industri tepung sagu Ako sudah efisien.

\section{KESIMPULAN}

1. Kegiatan dalam produksi tepung sagu Ako meliputi proses pengadaan bahan dasar, pengupasan, pembelahan, pemarutan, penyaringan, pengendapan, pengeringan, dan penggilingan, selanjutnya tepung dikemas dalam karung $25 \mathrm{~kg}$ dan siap untuk dijual.

2. Besaran biaya yang dikeluarkan Industri Rumahtangga Ako untuk memproduksi tepung sagu sebanyak per 17 ton/ bulan memerlukan total biaya sebesar Rp 258.669,39/ jam. Biaya total meliputi biaya tetap sebesar Rp3.717,47/ jam.dan biaya variabel sebesar Rp 254.951,92/ jam

3. Total pendapatan industri tepung sagu ako ialah $\mathrm{Rp} 410.576,92 /$ jam. Pendapatan diperoleh dari hasil penjualan tepung sagu kelas A sebesar 14 ton dan tepung sagu kelas B sebesar 3 ton untuk sebulan produksi. Pendapatan aktual industri Ako sebesar Rp 151.907,53/ jam.

4. Hasil perhitungan analisa kelayakan di industri tepung sagu ako jumlah pendapatan dibanding total biaya produksi memiliki nilai 1,59. Karena nila $\mathrm{R} / \mathrm{C}$ lebih besar daripada 1 maka usaha industri tepung sagu ako menguntungkan dan layak untuk diusahakan.

\section{SARAN}

1. Biaya dapat ditekan dengan mengoptimalkan pemeliharaan dan perbaikan pada alat yang digunakan sehingga bisa memperpanjang masa pakai alat. Selain itu biaya juga bisa diminimalisasikan dengan meningkatkan produktivitas kerja alat 
dan mengoptimalisaikan kerja karyawan.

2. Disarankan agar industri tepung sagu ako memperluas relasi untuk mendapatkan bahan dasar, agar tidak kekurangan bahan dasar dan produksi terus dilakukan. Melakukan penanaman dan meninggalkan benih sagu agar tumbuhan sagu dapat dipanen secara berkelanjutan.

\section{DAFTAR PUSTAKA}

Alfons JB, Rivaie AA. 2011. Sagu Mendukung Ketahanan Pangan Dalam Menghadapi Dampak Perubahan Iklim. Jurnal Perspektif. 10 (2): 81 - 91

Badan Pusat Statistik. 2017. Provinsi Kalimantan Barat Dalam Angka. BPS Provinsi Kalimantan Barat.

Baridwan, Zaki. 2008. Sistem Akuntansi Penyusunan Prosedur dan Metode. Edisi Kelima. BPPE. Yogyakarta.

Direktorat Jenderal Perkebunan. 2017. Statistik Perkebunan Indonesia 2015-2017, Sagu. Direktorat Jenderal Perkebunan. Jakarta.

Firdaus M. 2008. Manajemen Agribisnis. PT. Bumi Aksara. Jakarta.
Homas J. 2001. Pemasaran dan pasar. Cet. Ke-1. Gema insani press. Jakarta

Kuswadi 2005. Meningkatkan Laba Melalui Pendekatan Akuntansi Keuangan dan Akuntasi Biaya. Jakarta (ID): PT. Elex Media Komputindo.

Maherawati RB, Lestari, Haryadi. 2011. Karakteristik pati dari batang sagu kalimantan barat pada tahap pertumbuhan yang berbeda. Agritech. 31 (1): 9 - 13

Miller RL dan Meiners RE. 2000. Teori Mikroekonomi Intermediate. Munandar $\mathrm{H}$ penerjemah; Jakarta. Terjemahan dari PT Raja Grafindo Persada.

Mulyadi. 2005. Akuntansi Biaya, edisi ke6. Yogyakarta: STIE YKPN.

Nugroho B. 2002. Analisis Biaya Proyek Kehutanan. YPFK. Bogor.

Soekartawi. 2003. Teori Ekonomi Produksi. PT. Raja Grafindo Persada. Jakarta.

Suratiyah K. 2008. Ilmu Usahatani. Penebar Swadaya. Jakarta.

Timisela NR, 2006. Analisis Usaha Sagu Rumahtangga dan Pemasarannya. Jurnal Agroforestri. 1 (3) : 57 - 64 